\title{
CHARACTERISTICS OF NICOTINIC AND MUSCARINIC SECRETORY RESPONSES IN THE RAT ADRENAL MEDULLA STUDIED BY REAL-TIME MONITORING OF CATECHOLAMINE RELEASE
}

\author{
Akira Warashina ${ }^{1}$, NaOshi Fujiwara $^{2}$ and Koki Shimoji ${ }^{2}$ \\ Departments of ${ }^{1}$ Physiology and ${ }^{2}$ Anesthesiology, Niigata University School of Medicine, Niigata 951, \\ Japan
}

\begin{abstract}
Secretory responses in the perfused rat adrenal medulla stimulated by cholinergic agonists were studied by real-time monitoring of catecholamine (CA) release. Nicotinic response evoked by $10 \mu \mathrm{M}$ nicotine (or $100 \mu \mathrm{M}$ acetylcholine (ACh) in the presence of $1 \mu \mathrm{M}$ atropine) was distinct in various aspects from muscarinic response evoked by $100 \mu \mathrm{M}$ muscarine (or $\mathrm{ACh}$ in the presence of $1 \mathrm{mM}$ hexamethonium). During a continuous nicotinic stimulation, CA release rapidly increased to a peak and declined exponentially with a time constant of about $80 \mathrm{sec}$ close to a basal level. The nicotinic response was inhibited by $\mathrm{Ca}^{2+}$ channel blocker, either nifedipine or $\mathrm{Cd}^{2+}$. The muscarinic response consisted of a brief, initial phase of CA release followed by a maintained secretion. Both phases of the muscarinic response were not suppressed by $30 \mu \mathrm{M}$ nifedipine but inhibited by $200 \mu \mathrm{M} \mathrm{Cd}^{2+}$. Furthermore, adrenaline and noradrenaline were nonselectively secreted in response to the nicotinic stimulation whereas adrenaline was selectively released to the muscarinic stimulation. During the initial 4 min of stimulation with $100 \mu \mathrm{M} \mathrm{ACh}$, the amount of CA (adrenaline plus noradrenaline) secretion mediated by nicotinic ACh receptors was comparable with that mediated by muscarinic $\mathrm{ACh}$ receptors and the addition of both contributions roughly reconstituted the total CA secretion caused by a simultaneous stimulation of both types of ACh receptors. When adrenal medullae were stimulated through the splanchnic nerve, only the nicotinic secretory response took place predominately.
\end{abstract}

A number of studies have been carried out to clarify pharmacologic properties of acetylcholine (ACh) receptors on adrenal medulla cells. On this subject, however, there exists considerable confusion in the literature partly because types of $\mathrm{ACh}$ receptors and their contributions to the catecholamine (CA) secretion seem to be different in different animal species from which adrenal medulla cells under study are derived. For instance, bovine adrenal medulla cells secreted little CA by application of muscarinic agonists $(16,21)$ while muscarinic $\mathrm{ACh}$ receptors (in addition to nicotinic ACh receptors) played a substantial role for the CA secretion in the cat (5), dog $(17,18)$, rat $(19,23)$ and guinea pig $(11,14)$. In the chicken adrenal medulla (8), on the other hand, the secretory response was mediated only through muscarinic ACh receptors.

Another kind of confusion may arise on 
comparing results obtained from in vivo secretion experiments with those from in vitro experiments since relative contributions of nicotinic and muscarinic $\mathrm{ACh}$ receptors to adrenal CA secretion are known to depend in some case on whether ACh was applicd exogenously through perfusion medium or derived endogenously by splanchnic nerve stimulation (19).

In this study, properties of nicotinic and muscarinic ACh receptors in the perfused rat adrenal medulla are characterized in detail using a real-time CA monitoring method. The type of $\mathrm{ACh}$ receptors involved in the CA secretion that is evoked by electric stimulation of the splanchnic nerve is also examined.

\section{MATERIALS AND METHODS}

Perfusion of the rat adrenal gland was carried out with a modification of the method described previously (20). In brief, the left adrenal gland of male Wistar rats $(300-500 \mathrm{~g})$ was removed under sodium pentobarbital anesthesia and perfused retrogradely at a rate of $0.15 \mathrm{ml} / \mathrm{min}$ through a cannula inserted into the adrenal vein. The solution with which the gland was perfused was selected according to stimulus protocol with a 6-way rotary valve (Rheodyne) and introduced by a roller pump into the gland. The gland was sealed in an airtight chamber made of a disposable tip of a 5$\mathrm{ml}$ hand pipette. The perfusate was led into a flow cell (TL-5; Bioanalytical Systems) in which glassy carbon electrodes were embedded. The active and reference electrodes of the cell were connected to an electric controller (LC-4B; Bioanalytical Systems) for a continuous electrochemical detection of catecholamine in the perfusate. In some experiments, adrenals were dissected out together with a subdiaphragmatic part of the splanchnic nerve. In these preparations, the secretory response could be evoked by electric stimulation of the nerve with a pair of $\mathrm{Ag}-\mathrm{AgCl}$ electrodes set in the chamber.

In usual measurements, the applied voltage to the carbon electrodes in the detector cell was adjusted to $0.4-0.45 \mathrm{~V}$ to obtain $10-20 \mathrm{nA}$ of the oxidation current when a standard solution containing $1 \mu \mathrm{M}$ adrenaline was passed at a rate of $0.15 \mathrm{ml} / \mathrm{min}$. Under this condition, less than $6 \%$ of the total catecholamine in the perfusate was oxidated in the detector cell during measurement. The detector output, after I-V conversion, was sampled at a frequency of $0.5 \mathrm{~Hz}$ with an 8-bit digital memory and stored in a magnetic disk. Records presented in this paper were drawn, by D-A conversion of the digitalized data, with an X-Y recorder.

The catecholamine (adrenaline plus noradrenaline) output in its necessary part of response was numerically calculated from the digitalized record by referring to the size of response elicited with the standard adrenaline solution.

In order to measure adrenaline and noradrenaline secretions separately, high performance liquid chromatography with electro-chemical detection (HPLC-ECD) was employed. For this analysis, the perfusate from the outlet of the detector cell was collected into tubes which contained perchloric acid and EDTA (ethylenediaminetetraacetic acid) at final concentrations of $0.4 \mathrm{M}$ and $5 \mathrm{mM}$, respectively. After perfusion experiments, catecholamines of each gland were extracted by $0.8 \mathrm{M}$ perchloric acid and $10 \mathrm{mM}$ EDTA and assayed by HPLC-ECD.

A modified Krebs solution (MK solution) was used as the standard medium of the gland. The MK solution consisted of (mM) 150 $\mathrm{NaCl}, 5.6 \mathrm{KCl}, 2 \mathrm{CaCl}_{2}, 1 \mathrm{MgCl}_{2}, 5.6$ glucose, $1 \mathrm{NaH}_{2} \mathrm{PO}_{4}$-10 HEPES (4-(2-hydroxyethyl)-1piperazineethanesulfonic acid) buffered to pH 7.3 with $\mathrm{NaOH}$. Perfusion solutions were bubbled with $100 \% \mathrm{O}_{2}$. The perfusion experiment was performed at temperatures of 23$26^{\circ} \mathrm{C}$.

\section{RESULTS}

\section{Real-time Monitoring of ACh-induced Catecholamine Secretion}

The change in oxidation current presented in Fig. 1a is associated with the CA secretion from a rat adrenal gland stimulated 3 times by $100 \mu \mathrm{M} \mathrm{ACh}$ at $20.5 \mathrm{~min}$ intervals. During each stimulation lasting for $5.5 \mathrm{~min}$, the $\mathrm{CA}$ output increases rapidly, attaining the maximum within $80 \mathrm{sec}$, and then declines due to desensitization. The amount of catecholamine (adrenaline plus noradrenaline) which was released during the initial $4 \mathrm{~min}$ of 
a

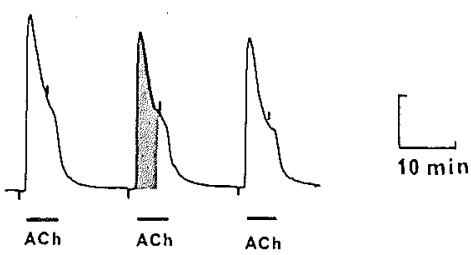

b

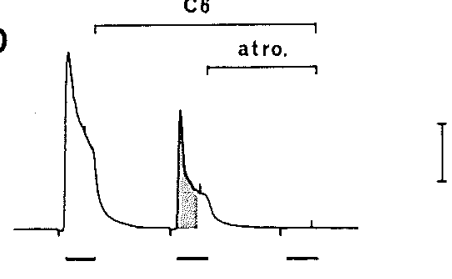

C

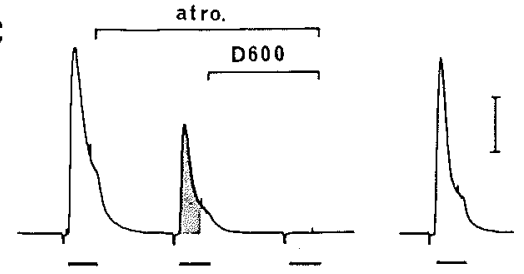

Fig. 1 Effects of hexamethonium (C6), atropine (atro.) and D600 on CA secretion from rat adrenal medullae stimulated by ACh. The traces show changes in the oxidation current associated with the CA secretion under the following conditions. a: The adrenal medulla was exposed for $5.5 \mathrm{~min}$ to $100 \mu \mathrm{M} \mathrm{ACh}$ at 20.5 -min intervals (3 times) as marked with the horizontal bars underneath the trace. b: As indicated above the trace, the second stimulation with $100 \mu \mathrm{M}$ ACh was performed in the presence of $1 \mathrm{mM} \mathrm{C} 6$, and $1 \mu \mathrm{M}$ atropine was further added to the perfusion medium prior to the third stimulation. $\mathrm{c}$ : The second stimulation with $100 \mu \mathrm{M} \mathrm{ACh}$ was performed in the presence of $1 \mu \mathrm{M}$ atropine, and $100 \mu \mathrm{M}$ D600 was further added prior to the third stimulation. After a 40 -min washout, the fourth stimulation was carried out to show the recovery of the response. The downward and upward blips beside the traces indicate, respectively, the moments of $\mathrm{ON}$ and OFF switching of the valve to introduce $\mathrm{ACh}$-containing Krebs solution. The vertical bar in each frame denotes the intensity of the oxidation current $(20-28 \mathrm{nA})$ obtained with standard solution ( $2 \mu \mathrm{M}$ adrenaline), corresponding to CA output at a rate of $300 \mathrm{pmol} /$ min. Adrenaline and noradrenaline outputs during the shaded portions of the responses were assayed by HPLC-ECD and the results are shown in Fig. 2.

the first stimulation was $1,820 \pm 550 \mathrm{pmol}$ (mean $\pm S D$ ) when perfusates from 18 experiments were analyzed by HPLC-ECD. In the corresponding period for the second stimulation (the shaded portion in Fig. 1a), the CA output was $84 \%$ of that for the first stimulation. Since the CA output due to the first stimulation amounted to only $4 \%$ of the total CA in the gland, a major portion of the decrease is due to the desensitization that developed during the first exposure to ACh and still remains after the 15 -min washout. The similar is shown for the third stimulation.

It was shown in previous works $(19,23)$ that both nicotinic and muscarinic ACh receptors contributed to the catecholamine secretion in the perfused rat adrenal medulla. To select CA secretion mediated by muscarinic ACh receptors, in this study, the second stimulation with $\mathrm{ACh}$ is applied in the presence of a nicotinic ACh blocker, hexamethonium (C6) as shown in Fig. 1b. This C6-resistive response solely consists of the muscarinic partition of the CA secretion since addition of atropine in the C6containing medium completely abolishes the response as shown in the third stimulation with ACh (Fig. 1b).

On the other hand, the nicotinic partition of the ACh-evoked secretion is shown as the second response in Fig. 1c, where an adrenal medulla was stimulated by $\mathrm{ACh}$ in the presence of atropine. This nicotinic response is completely suppressed by $100 \mu \mathrm{M}$ D600 added to the medium, suggesting that the secretion is triggered by a calcium entry through voltage-dependent $\mathrm{Ca}^{2+}$ channels as has been shown in previous studies $(6,15-17)$.

\section{Nicotinic and Muscarinic Contributions in ACh-evoked CA Secretion}

The nicotinic and muscarinic secretory responses are quantitatively compared using data obtained from experiments such as shown in Fig. 1. Namely, the amounts of adrenaline (open columns in Fig. 2) and noradrenaline (hatched columns) released during the second stimulation (initial $4 \mathrm{~min}$ ) are illustrated after normalization of them to the total CA output during the first stimulation. The addition of the nicotinic CA secretion ( 0.41 as denoted by the column $b$ ) to the muscarinic CA secretion ( 0.35 by the column c) roughly reconstitutes the total CA secretion $(0.81$ by the column a) which was obtained in the medium containing no ACh-blocking agents. 


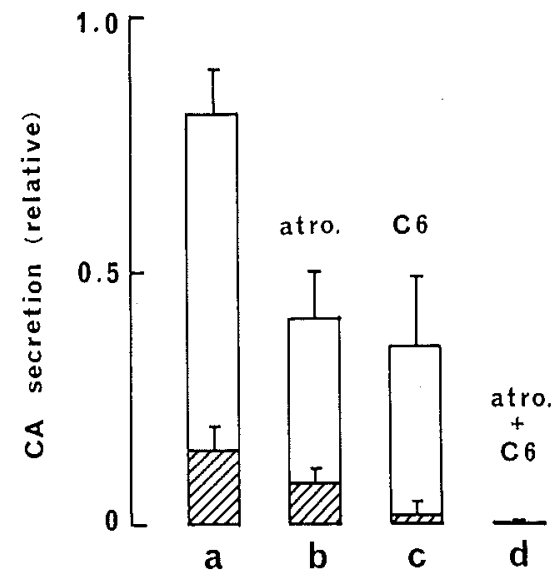

Fig. 2 Relative amounts of adrenaline (the open columns) and noradrenaline (the hatched columns) released from adrenal medulla stimulated by $100 \mu \mathrm{M} \mathrm{ACh}$ under the following conditions; $\mathrm{a}$, in the absence of ACh-receptor blocking agents; $b$, in the presence of $1 \mu \mathrm{M}$ atropine; $\mathrm{c}$, in the presence of $1 \mathrm{mM} \mathrm{C} 6$; $\mathrm{d}$, in the presence of both $1 \mu \mathrm{M}$ atropine and $1 \mathrm{mM}$ C6. The sample perfusates to assay for adrenaline (A) and noradrenaline (NA) were collected during the initial $4 \mathrm{~min}$ of the first and second responses in the experimental protocol as shown in Fig. 1. In each determination, the amounts of A and NA released by the second stimulation were normalized to the catecholamine (A+ NA) released by the first stimulation. Vertical lines denote standard deviations from 4 independent experiments.

Fig. 2 also shows that the molar ratio of noradrenaline to adrenaline (NA/A ratio) in the muscarinic secretion is $0.025 \pm 0.020$ $(\mathrm{n}=5)$, which is apparently smaller than $0.25 \pm 0.07$, the NA/A ratio found in the nicotinic secretion. The latter figure is close to the mean NA/A ratio $(0.28 \pm 0.04, \mathrm{n}=5)$ in the adrenal glands used in the experiments for the nicotinic stimulation. The NA/A ratio in the ACh-evoked secretion with no ACh-blocking agents lies between the above two figures.

\section{$C A$ Secretions Evaluated by the Real-time Measurement}

The validity of the real-time measurement of CA secretion may be assessed using the results obtained from experiments illustrated in Figs. 1 and 2. For the purpose, areas under response curves of the real-time measure- ment, in portions where perfusates were sampled for $\mathrm{CA}$ assay, were evaluated by numerical integration using data stored in magnetic disks, and they were converted into the amounts of CA in the perfusates by referring to the size of response area associated with the standard adrenaline solution. The values thus obtained were highly proportional to the amounts of CA detected by HPLC$\mathrm{ECD}$ in the sample perfusates.

However, absolute amounts of CA calculated from the response curves were found to be systematically larger than those determined by HPLC-ECD by a factor of $1.25 \pm 0.23$ $(n=18)$, even after the decrease in CA concentration due to the electrochemical reaction which should have taken place on the detector electrode (less than 6\% of the total CA released) was corrected. Although the secretion of ascorbic acid along with CA produces an additional oxidation current, this is estimated to be only $1 \%$ of the total current since ascorbic acid content is about $4 \%$ of total CA in rat chromaffin granules (22) while the current generated by ascorbic acid under the condition of our real-time measurement was one-fifth of that produced by equimolar adrenaline. In this study, we could not locate the source of the disagreement between the two different CA determinations. However, any descriptions in the present paper are not affected by this slight, systematic discrepancy.

\section{Effects of $\mathrm{Ca}^{2+}$ Channel Blockers on Nicotinic and Muscarinic Secretions}

The time course of CA secretion evoked by $100 \mu \mathrm{M}$ ACh in the presence of $1 \mu \mathrm{M}$ atropine is shown in Fig. 3Aa. The secretion is attenuated exponentially with a time constant of $78 \pm 19 \sec (n=5)$ close to the basal level during the continuous stimulation. A comparable amount of $\mathrm{CA}$ is released by $10 \mu \mathrm{M}$ nicotine as shown in Fig. 3Ab. When exposed to nicotine in prolonged periods, the time course of the secretion was very similar to that in Fig. 3Aa (data not shown here). The nicotineevoked secretion (and also ACh-evoked secretion in the presence of atropine) is suppressed with $30 \mu \mathrm{M}$ nifedipine by $95 \pm 3 \%(\mathrm{n}=3)$ of that with no nifedipine (Fig. $3 \mathrm{Bb}$ ). $\mathrm{Cd}^{2+}$ also suppressed the nicotinic secretory response, 
A
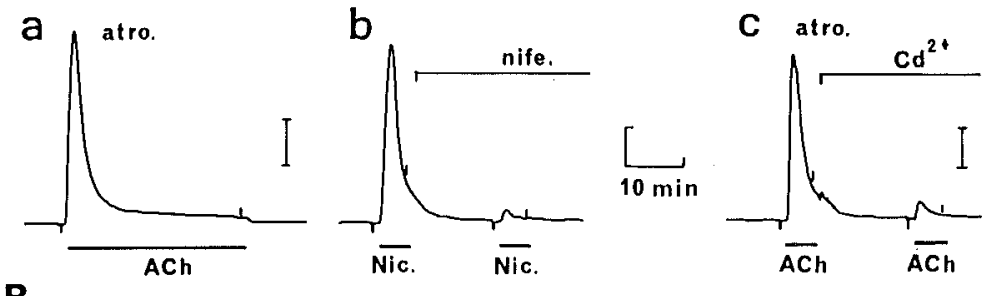

$\mathbf{B}$
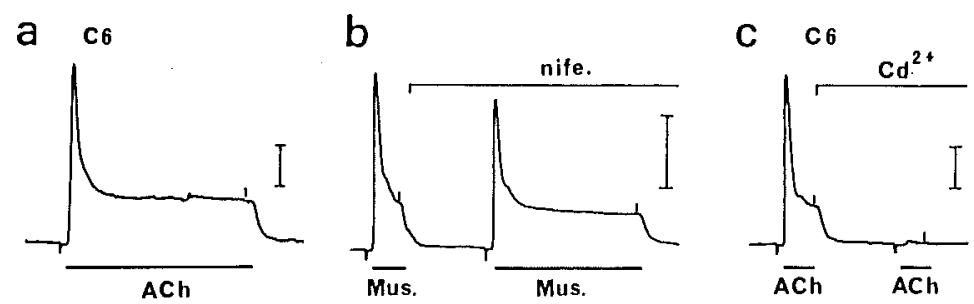

Fig. 3 Effects of $\mathrm{Ca}^{2+}$-channel blocking agents on the CA secretion mediated by nicotinic and muscarinic ACh receptors. A: Nicotinic secretory response was induced by $100 \mu \mathrm{M} \mathrm{ACh}$ in the presence of $1 \mu \mathrm{M}$ atropine in a and $\mathrm{c}$, or by $10 \mu \mathrm{M}$ nicotine in $\mathrm{b}$. The second stimulations in $\mathrm{b}$ and $\mathrm{c}$ were performed in the presence of $30 \mu \mathrm{M}$ nifedipine and $200 \mu \mathrm{M} \mathrm{Cd}^{2+}$, respectively. B: Muscarinic secretory response was induced by $100 \mu \mathrm{M} \mathrm{ACh}$ in the presence of $1 \mathrm{mM}$ hexamethonium (C6) in a and c, or by $100 \mu \mathrm{M}$ muscarine in $\mathrm{b}$. The second stimulations in $\mathrm{b}$ and $\mathrm{c}$ were performed in the presence of $10 \mu \mathrm{M}$ nifedipine and $200 \mu \mathrm{M} \mathrm{Cd}^{2+}$, respectively. The periods in which the adrenal medullae were exposed to the stimulants are indicated underneath the traces, and the periods perfused with nifedipine- or $\mathrm{Cd}^{2+}$-containing Krebs solution are shown above the traces. The vertical bars represent the oxidation current obtained with $1 \mu \mathrm{M}$ adrenaline.

showing a $91 \pm 4 \%(\mathrm{n}=3)$ inhibition at $200 \mu \mathrm{M}$ (Fig. 3c) and a complete inhibition at $500 \mu \mathrm{M}$.

The time course of muscarinic secretory response evoked by $\mathrm{ACh}$ in the presence of $1 \mathrm{mM} \mathrm{C6}$ (Fig. 3Ba) is dissimilar to that of the nicotinic response (Fig. 3Aa). The initial phase of the muscarinic response consisted of a very sharp peak with a duration of $80 \pm 11 \mathrm{sec}$ $(\mathrm{n}=5)$ at half-height, which is significantly shorter than $114 \pm 14 \mathrm{sec}(\mathrm{n}=5)$, that for the nicotinic secretory response. The muscarinic response is also characterized by a high level of the maintained secretion which lasts as long as the stimulation is present (Fig. 3Ba).

It is noted that the secretion evoked by $100 \mu \mathrm{M}$ muscarine (Fig. 3Bb) or $100 \mu \mathrm{M} \mathrm{ACh}$ in the presence of $\mathrm{C} 6$ is not affected by 30 $\mu \mathrm{M}$ nifedipine. The $\mathrm{CA}$ secretion during the initial $4 \mathrm{~min}$ of the second stimulation with these drugs ( 2 experiments with muscarine and 3 with $\mathrm{ACh}$ plus $\mathrm{C} 6$ ) in the presence of nifedipine was $82 \pm 13 \%$ of that during the first stimulation. The same quantity in the absence of nifedipine was $85 \pm 6 \%$. There is no significant difference between the above two figures ( $t$-test, $P>0.05$ ).

On the other hand, $\mathrm{Cd}^{2+}$ suppressed the muscarinic response completely at $500 \mu \mathrm{M}$, by $96 \pm 3 \%(\mathrm{n}=3)$ at $200 \mu \mathrm{M}$ (Fig. $3 \mathrm{Bc}$ ) and $72+5 \%(\mathrm{n}=3)$ at $50 \mu \mathrm{M}$.

\section{Catecholamine Secretion Induced by Nerve Stimulation}

A marked CA release is elicited by an electrical stimulation to the splanchnic nerve with 1msec pulses to $10 \mathrm{~V}$ at $20 \mathrm{~Hz}$. The secretion declines rapidly over the period of continuous stimulations as shown in Fig. 4 (the left and right peaks). In the presence of $1 \mathrm{mM} \mathrm{C6}$ (middle), however, the same electrical stimulation to the nerve induces only a trace 


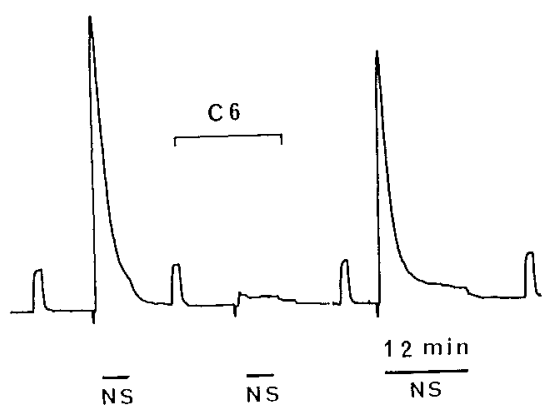

Fig. 4 Effect of hexamethonium (C6) on the catecholamine secretion evoked by electric stimulation of the splanchnic nerve. The nerve was stimulated, during the periods indicated by the horizontal bars labelled NS, with $1-\mathrm{msec}$ pulses to $10 \mathrm{~V}$ at a frequency of $20 \mathrm{~Hz}$. C6 at $1 \mathrm{mM}$ was presented during the second period of stimulation. Four calibration responses before and after the nerve stimulations were elicited with standard solution of $1 \mu \mathrm{M}$ adrenaline.

amount of CA secretion $(5.7 \pm 3.4 \%(n=8)$ of the first response). After a washout of $\mathrm{C} 6$, the secretory response to the nerve stimulation recovers (right peak). The result suggests that ACh released from splanchnic nerve terminals effectively stimulates nicotinic $\mathrm{ACh}$ receptors but a very limited fraction of the released $\mathrm{ACh}$ reaches muscarinic $\mathrm{ACh}$ receptors on rat adrenal medulla cells.

\section{DISCUSSION}

\section{Real-time Monitoring of CA Secretion from the Rat Adrenal Gland}

In this study, real-time monitoring of CA secretion from the rat adrenal gland was performed by electrochemical detection of CA. The method similar to this has been developed with the isolated cat adrenal gland by Borges et al. (2) and with the rat adrenal gland in situ by Kumakura et al. (9). The method is particularly useful for studying precise time courses of CA secretions in response to various chemical stimuli as well as electric nerve stimulation. The validity of the method was already described by the above authors. We also confirmed an excellent proportional relation between the intensity of oxidation current in the real-time measurement and the amount of CA detected by HPLC-ECD in sample perfusates.

\section{Nicotinic and Muscarinic Contributions in ACh-evoked CA Secretion}

Involvement of both nicotinic and muscarinic $\mathrm{ACh}$ receptors in ACh-evoked CA secretion from perfused rat adrenal medulla has been described in previous papers $(10,23)$. The present study confirmed this fact and further documented distinct characteristics of the secretory responses mediated by the two classes of $\mathrm{ACh}$ receptors. The different time courses of the secretory responses elicited by nicotine (or $\mathrm{ACh}$ in the presence of atropine) and muscarine (or $\mathrm{ACh}$ in the presence of $\mathrm{C} 6$ ) were found by means of the real-time measurement. The nicotinic secretory response during a continuous stimulation decreased exponentially, probably due to the desensitization of nicotinic ACh receptors, until the CA output went down close to the basal level whereas the muscarinic response exhibited a maintained secretion that lasted as long as the stimulation was continued. The maintained secretion as well as the initial, spiky output increased with increasing concentration of $\mathrm{ACh}$ up to $1 \mathrm{mM}$ in the presence of C6 (data not shown). This suggests that unlike nicotinic receptors, muscarinic $\mathrm{ACh}$ receptors are not desensitized by an exposure to concentrated ACh.

Recently, Malhotra et al. (10) reported the time course of CA secretion, with a 5 -min time resolution, from the perfused rat adrenal stimulated by nicotine or muscarine. As compared their results with ours, the basic features of the time courses of the nicotinic and muscarinic responses are commonly shown. In detail, however, some differences are recognized. The initial, spiky phase of the muscarinic response (Fig. 3Ba) is absent in their measurement. The nicotinic response in our measurement declined faster due to desensitization than that in theirs, showing about $1 \mathrm{~min}$ and $15 \mathrm{~min}$ for half-decay, respectively. These discrepancies, however, seem to be derived, at least partially, by the low timeresolution of CA detection in their experiments, with which transient changes, particularly the initial peak phases, may be smoothed out in the detection.

It was shown that the muscarinic stimulation selectively evoked adrenaline release while the nicotinic stimulation caused both 
adrenaline and noradrenaline secretions nonselectively. The preferential secretion of adrenaline over noradrenaline on stimulating muscarinic receptors was already reported with the cat adrenal medulla (3). Wakade and Wakade (19) also reported that muscarine preferentially evoked adrenaline secretion in the rat adrenal medulla, showing that the NA/A ratio was 0.212 with muscarine while it was 0.289 with nicotine. In this study, the NA/A ratio with muscarine was found to be 0.025 , which is far smaller than their figure. The reason for this discrepancy is not clear.

Concerning the impotency of muscarine to secrete noradrenaline, the following two cases are conceivable; noradrenaline-secreting cells in those adrenal medullae may either have fewer number of muscarinic receptors or they induce weaker intracellular secretory processes after stimulation of muscarinic $\mathrm{ACh}$ receptors.

\section{Mechanisms of the CA Secretion through Nicotinic and Muscarinic ACh Receptors}

It was shown that $\mathrm{Ca}^{2+}$ channel blockers could be used to characterize the difference between nicotinic and muscarinic responses. The blockade of $\mathrm{Ca}^{2+}$ channels either by nifedipine or $\mathrm{Cd}^{2+}$ inhibited the CA secretion evoked by nicotinic stimulation (Fig. 3A, b and c). This suggests that the nicotinic secretory response in chromaffin cells is associated with an increased $\mathrm{Ca}^{2+}$-influx through voltage-dependent $\mathrm{Ca}^{2+}$ channels (presumably classified by L-type based on nifedipine and $\mathrm{Cd}^{2+}$ sensitivities; 12,13$)$ which are activated by nicotinereceptor-mediated depolarization.

In the muscarinic response, on the other hand, the CA secretion was not affected by nifedipine (Fig. 3Bb). In rat adrenal chromaffın cells, a poor sensitivity of the muscarinic secretory response to an organic $\mathrm{Ca}^{2+}$ channel blocker (verapamil) was reported by Harish et al. (6). They further showed that the CA secretion evoked by muscarine persisted in a low $\mathrm{Ca}^{2+}$ medium. They suggested from these observations that muscarine induced the production of a second messenger (such as inositol trisphosphate; 1) which in turn mobilized intracellular $\mathrm{Ca}^{2+}$ to promote the secretory process. However, it was found in this study that the muscarinic secretory response was inhibited by $\mathrm{Cd}^{2+}$ (Fig. $3 \mathrm{Bc}$ ). This argues against the above notion that the intracellular $\mathrm{Ca}^{2+}$ store plays an essential role for the muscarine-evoked secretion if $\mathrm{Cd}^{2+}$ exerts its effect exclusively on $\mathrm{Ca}^{2+}$ channels to block $\mathrm{Ca}^{2+}$-influx. At present, however, we can not rule out a possibility that a very small amount of $\mathrm{Cd}^{2+}$ may enter chromaffin cells and interfere with intracellular secretory process.

As another possibility, the activation of muscarinic receptors on chromaffin cells may induce a $\mathrm{Ca}^{2+}$-influx which is not inhibited by nifedipine but by $\mathrm{Cd}^{2+}$. There are now various, novel proposals $(4,7)$ in which second messengers or GTP-binding proteins in various cell types could activate non-traditional $\mathrm{Ca}^{2+}$ channels to induce $\mathrm{Ca}^{2+}$-influx to trigger cellular responses following agonist-receptor interactions.

We studied previously the characteristics of the CA secretion induced by bradykinin (20). Bradykinin-stimulated rat adrenal medulla cells selectively secreted adrenaline and this secretion was not suppressed by methoxyverapamil (D600) but inhibited by $\mathrm{Co}^{2+}$. Moreover, the time course of bradykinininduced secretion quite resembled that of muscarine-induced secretion, exhibiting a brief, initial output followed by a maintained secretion. These characteristics coincide all with those of muscarine-evoked secretion presented in this study. We therefore presume the occurrence of common intracellular processes in muscarine- and bradykinin-evoked secretions.

\section{ACh Receptors Activated by Splanchnic Nerve Stimulation}

The CA secretion caused by stimulation of splanchnic nerve contained a very little muscarinic contribution (Fig. 4). Wakade and Wakade (19) have reported a similar result when the nerve in the adrenal gland was transmurally stimulated. It seems that nicotinic receptors are concentrated in the synaptic region on rat adrenal medullary cells while most of muscarinic receptors occur in the extrajunctional region.

We wish to thank Professor Takehiko Bando for helpful discussion, and Mr Shuji Wakui and $\mathrm{Mr}$ Yukio Sato for their help during the course of this 
study. We also thank Dr K. Kumakura (Sophia University in Tokyo) for valuable advice concerning the real-time catecholamine monitoring technique used in this study.

\section{Received for publication 20 February 1989}

\section{REFERENCES}

1. BerRidge M. J. and Irvine R. F. (1984) Inositol trisphosphate, a novel second messenger in cellular signal transduction. Nature 312, 315-321

2. Borges R., Sala F. and García A. G. (1986) Continuous monitoring of catecholamine release from perfused cat adrenals. J. Neurosci. Meth. 16, 289-300

3. Douglas W. W. and Poisner A. M. (1965) Preferential release of adrenaline from the adrenal medulla by muscarine and pilocarpine. Nature 208, 1102-1103

4. Exton J. H. (1988) Mechanisms of action of calcium-mobilizing agonists: some variations on a young theme. FASEB J. 2, 2670-2676

5. Feldberg W., Minz B. and Tsudzimura H. (1934) The mechanism of the nervous discharge of adrenaline. J. Physiol. 81, 286-304

6. Harish O. E., Kao L.-S., Raffaniello R., WAKADE A. R. and Schneider A. S. (1987) Calcium dependence of muscarinic receptormediated catecholamine secretion from the perfused rat adrenal medulla. J. Neurochem. $\mathbf{4 8 ,}$ $1730-1735$

7. Irvine R. F. and Moor R. M. (1986) Microinjection of inositol 1,3,4,5-tetrakisphosphate activates sea urchin eggs by a mechanism dependent on external $\mathrm{Ca}^{2+}$. Biochem. J. 240, 917-920

8. KNIGHT D. E. and BAKER P. F. (1986) Observations on the muscarinic activation of catecholamine secretion in the chicken adrenal. Netiroscience 19, 357-366

9. Kumakura K., Sato A. and Suzuki H. (1988) Direct recording of total catecholamine secretion from the adrenal gland in response to splanchnic nerve stimulation in rats. $J$. Neurosci. Meth. 24, 39-43

10. Malhotra R. K., Wakade T. D. and Wakade A. R. (1988) Comparison of secretion of catecholamines from the rat adrenal medulla during continuous exposure to nicotine, muscarine or excess K. Neuroscience 26, 313-320

11. Nakazato Y., Ohga A., Oleshansky M., Tomita U. and Yamada Y. (1988) Voltage-independent catecholamine release mediated by the activation of muscarinic receptors in guinea-pig adrenal glands. Brit. J. Pharmacol. 93, 101-109

12. Narahashi T., Tsunoo A. and Yoshil M. (1987) Characterization of two types of calcium channels in mouse neuroblastoma cells. $J$. Physiol. 383, 231-249

13. Nowycky M. C., Fox A. P. and Tsien R. W. (1985) Three types of neuronal calcium channel with different calcium agonist sensitivity. Nature 316, 440-443

14. Role L. W. and Perlman R. L. (1983) Both nicotinic and muscarinic receptors mediate catecholamine secretion by isolated guinea-pig chromaffin cells. Neuroscience 10, 979-985

15. Schneider A. S., Cline H. T., Rosenheck K. and Sonenberg M. (1981) Stimulus-secretion coupling in isolated adrenal chromaffin cells: calcium channel activation and possible role of cytoskeletal elements. J. Neurochem. 37, 567575

16. Schneider A. S., Herz R. and Rosenheck K. (1977) Stimulus-secretion coupling in chromaffin cells isolated from bovine adrenal medulla. Proc. Natl. Acad. Sci. USA 74, 50365040

17. Sumikawa K., Matsumoto T., IshizaKa N., NAGAI H., AMENomori Y. and AmaKaTa Y. (1982) Mechanism of the differential effects of halothane on nicotinic- and muscarinic-receptor mediated responses of the dog adrenal medulla. Anesthesiology 57, 444-450

18. Tsujimoto A. and Nishikawa T. (1975) Further evidence for nicotinic and muscarinic receptors and their interaction in dog adrenal medulla. Eur. J. Pharmacol. 34, 337-344

19. WAKADE A. R. and WaKAdE T. D. (1983) Contribution of nicotinic and muscarinic receptors in the secretion of catecholamines evoked by endogenous and exogenous acetylcholine. Nellroscience 10, 973-978

20. Warashina A., Fujimara N., Hirano T. and SHimoJı K. (1988) Characteristics of bradykinin-evoked secretory response in the perfused rat adrenal medulla. Biomedical Res. 9, 139-145

21. WiLSON S. P. and KirshNer N. (1977) The acetylcholine receptor of the adrenal medulla. $J$. Neurochem. 28, 687-695

22. Winkler H., Apps D. K. and Fischer-Colbrie R. (1986) The molecular function of adrenal chromaffin granules: Established facts and unresolved topics. Neuroscience 18, 261-290

23. Yoshizaki T. (1973) Participation of muscarinic receptors on splanchnic-adrenal transmission in the rat. Jap. J. Pharmacol. 23, 813-816 